Journal of Engineering and Applied Sciences 14 (3): 701-708, 2019

ISSN: 1816-949X

(C) Medwell Journals, 2019

\title{
Risk Assessment for Causes of Variation Orders for Residential Projects
}

\author{
${ }^{1}$ Abdallah Ali Kamal Balbaa, ${ }^{2}$ Omar Aly Mousa El-Nawawy, ${ }^{3}$ Karim Mohamed El-Dash and \\ ${ }^{4}$ Mohamed Badawy Abd El-Megeed Badawy \\ ${ }^{1}$ Department of Structural Engineering, Ain Shams University, ZIP Code:11762 Cairo, Egypt \\ ${ }^{2}$ Department of Structural Engineering, Ain Shams University, ZIP Code:11517 Cairo, Egyp \\ ${ }^{3}$ Department of Civil Engineering, Benha University, ZIP Code:11762 Al Qalyubia, Egypt \\ ${ }^{4}$ Department of Structural Engineering, Ain Shams University, ZIP Code:12651 Cairo, Egypt
}

\begin{abstract}
This study aims to assess risks caused by variation orders in construction projects in Egypt, through studying the most important causes of the variation orders in construction projects. A structured questionnaire was developed which contained 39 collected causes of change and categorized depending on the origin of the variation, owner related, consultant related, contractor related, project management related or other related variations. The survey was carried out among client representatives, consultants, contractors and project managers involved in delivering projects. A total of 153 received questionnaire sets out of 250 questionnaires distributed. The collected questionnaires were analyzed with Statistical Package for the Social Science "SPSS". The risk of each factor was analyzed by four different methods. The results of the study show that the most five risky causes of variation orders are "Change in economic conditions", "Lack of coordination between the parties", "Bad sub-contractor or supplier by the contractor", "Impediment to prompt decision-making process by the owner of the project" and "Contractor's financial difficulties".
\end{abstract}

Key words: Causes, construction projects, risk assessment, variation orders, construction projects, Egypt

\section{INTRODUCTION}

The variation is defined as any change or modification in the design, quality or quantity of the work as indicated on the drawings and described or referred to in the contract invoices (Mohammad et al., 2010). Orders of variation are a common phenomenon in construction projects in Egypt. Almost, all construction projects suffer from it. The causes of the variation are mainly due to the lack of equipment and materials, poor workmanship, complex design, technological progress and changes in working conditions. Variation orders affect not only the cost of the project but also could affect the completion dates as well. Variation is sometimes referred to as variation order, change order or variation instruction. This research identifies and ranks the factors causing variation in the construction industry in Egypt. It also compares between four different analysis methods to investigate how the analysis method can effect on raking.

The nature of variation order: Arain and Pheng (2005) classified variation in two types, useful and harmful variation. A helpful variation is a change created to improve quality, reduce budget, schedule or technical issues in a project (Ndihokubwayo, 2008). Harmful variation is the difference that negatively affects the value of the client or project performance. Arain and Pheng (2005) acknowledged four key assets for changes including the client, consultant, contractor and other changes.

Owner related variations: The change in the scope of the work or the project plan is almost due to many reasons such as illegal planning of the project or the failure of the owner to participate in the design phase, these changes may result in deviations from the amount specified in the contract (Memon et al., 2014; Arain et al., 2004). Owner's financial problems significantly affect project implementation because of the impact on the cash flow and the cost management plan. This may increase project time as they may force the owner to change the material, specifications or quality to reduce financial requirements (Hanif et al., 2016; Clough and Sears, 1994; O'Brien, 1998). Inadequate project objectives, the owner must define the project objectives. Otherwise, the designer may lose time during project design with many constraints that may cause changes during construction and affect project progress (Ibbs and Allen, 1995). Professionals should

Corresponding Author: Abdallah Ali Kamal Balbaa, Department of Structural Engineering, Ain Shams University, ZIP Code: 11762 Cairo, Egypt 
participate in the design phase to help clarify project objectives and recognize that their requirements are not met in the early stages (Memon et al., 2014). Replacement of materials can be due to landlord's financial problems or a change in specifications by the owner and this may lead to changes during the construction phase and changing procedures may result in differences in the method of application (Keane et al., 2010). An impediment to prompt decision-making process, owners, must make quick decisions, especially, during project construction in order to prevent any delay based on late owner's decisions, otherwise there will be a change in project schedule and cost (Sanvido et al., 1992; Gray and Hughes, 2001; Memon et al., 2014). The obstinate nature of the owner if the owner is obstinate, this may lead to change orders during the execution of the project due to the consequences of decisions and orders made by the owner that do not match the vision of the professional at later stages of the project (Wang, 2000; Arain et al., 2004; Memon et al., 2014). Change in specifications by owner. This may occur for many reasons such as insufficient project objectives or a change in design or financial problems (O'Brien, 1998; Hanif et al., 2016). Employer intervention may result in late intervention by the employer during the design stage and the construction phase and the delay in the review and approval may affect the progress of the project (Wu et al., 2004; Chan and Kumaraswamy, 1997).

Consultant related variations: Change in design by the consultant is mainly for design improvement. The consultant may have to make changes in design, specifically on projects that construction starts before the design is finished (Fisk, 1997; Arain et al., 2004). Also, this may occur when the design is revised by the consultant who may have a different view of the design or due to the rescheduling of work (Mohammad et al., 2010). The change in design by the consultant is mainly for improving the design, the consultant may resort to changes in design and specifically on projects that begin construction before the design is finished (Fisk, 1997; Arain et al., 2004). This may also occur when the consultant revised the design and may have a different opinion of the design or rescheduling of the work (Mohammed et al., 2010). Variation may occur due to errors and omissions in design drawings depending on the time of error detection (Arain et al., 2004; Keane et al., 2010). Any conflict in contract documents may increase in time and cost. So, contract documents must be clear and precise (Construction Industry Institute, 1986; Memon et al., 2014). If the final time of value engineering is delayed, it may lead to variation and increase costs.
Ideally, the implementation of value engineering must be completed before construction is initiated (Dell'Isola, 1982; Keane et al., 2010). Complex design needs special construction methods and skilled craftsmen. The more complex the design, the greater the chances of differences (Fisk, 1997; Arain et al., 2004; Memon et al., 2014). Insufficient details of work drawings may lead to misunderstandings of actual requirements, so drawings must be clear and fully detailed (Arain et al., 2004; Geok, 2002; Memon et al., 2014). The consultant must be aware and with good knowledge of available materials and equipment to produce comprehensive design (Geok, 2002; Keane et al., 2010). Inadequate design commonly causes variations in construction projects, so designers should develop appropriate design (Construction Industry Institute, 1990; Fisk, 1997; Memon et al., 2014). Change in the specification by the consultant commonly occurs due to inadequate project objectives. This may result in change requests and may increase the project budget and schedule (O'Brien, 1998; Memon et al., 2014). Poor work drawings may cause errors during construction, causing variations. These differences may affect the progress of the work, since, rework may be required that may cause delay and increase in cost (Geok, 2002; Arain et al., 2004; Keane et al., 2010).

Contractor related variations: Contractors have creative and practical ideas that make designs more actual and applicable many variations may occur because of the lack of involvement of the contractor in the design phase of the project (Arain et al., 2004; Keane et al., 2010). Contractors must have a good procurement and resource plan and any procurement problem may lead to variation during the construction phase and affect the completion of the project (O'Brien, 1998; Memon et al., 2014). Projects with new technologies need special resources and skilled manpower, variations may occur due to unavailability of skills and may affect the project schedule (Arain et al., 2004; Memon et al., 2014). The contractor's financial problems may affect the progress of the project due to financial obligations where the contractor must pay the worker's wages regardless of whether the owner pays the contractor or not and the failure of these obligations may affect the quality and implementation of the project (Thomas and Napolitan, 1995; Memon et al., 2014). The desire profitability of the contractor may cause variation as it is considered as additional financial rewards for additional works resulted from variations (O'Brien, 1998; Keane et al., 2010). Variation may occur due to unexpected site conditions such as different soil conditions or unforeseen problems in the construction of the substructure that could not be found during the 
contractor's site investigation which may require additional cost and time to be added and request changes (Fisk, 1997; O'Brien, 1998; Keane et al., 2010). Poor workmanship may result in demolition and rework that may affect project progress and increase project budget (Fisk, 1997; O'Brien, 1998). It would be difficult to the contractor with unfamiliar local conditions to carry out work that may result in variations and increase time and cost of the project (Clough and Sears, 1994; Keane et al., 2010). Fast-track construction needs a well-organized system to carry out the independent project activities otherwise high risk of variations may occur during construction that may affect project execution, increasing the total cost and the time of the project (Fisk, 1997; Keane et al., 2010). The poor procurement process may result in variations and affect project cycle, causing delay project completion (Fisk, 1997; Memon et al., 2014). Long lead procurements affect the project schedule and may affect project construction. The contractor may be forced to accelerate the construction process to deliver the project on time which may result in changes due to the increased cost and additional workmanship (Fisk, 1997; Keane et al., 2010). The supplier or subcontractor is a major problem, especially, if the site management is bad. It is highly anticipated that there will be poor coordination among sub-contractors of different disciplines and may lead to changes and delays of the project (Hsieh et al., 2004).

Project management related variations: Lack of coordination between parties may affect project execution and may result in variations and dissatisfaction of the owner (Arain et al., 2004). Lack of communication between parties has a negative effect on project execution and causes rework, demolition and major variations (Arain et al., 2004; Keane et al., 2010). Lack of strategic planning is normal in projects that construction starts before the finishing of the design (Clough and Sears 1994; O'Brien, 1998; Memon et al., 2014). The failure of meeting the safety regulations and requirements may cause variations. Also, safety is a very important factor to finish the project successfully (Clough and Sears, 1994; Keane et al. (2010).

Other related variations: Bad weather for outside activities may cause an increase of the overall duration and cost where extra days to be added to compensate the delayed days (Fisk, 1997; O'Brien, 1998; Keane et al., 2010). Change in economic conditions and regulations is one of the most significant factors that may cause variations on the project cost and may affect the duration of the project execution (Fisk, 1997; Keane et al., 2010).
Different socio-cultural backgrounds result in lack of coordination, communication and understanding between project team members that may lead to variations (O'Brien, 1998; Keane et al., 2010). Project progress may be affected by unexpected problems, if not resolved by professionals it may cause variations (Clough and Sears, 1994; O'Brien, 1998; Keane et al., 2010). Force majeure can have obvious repercussions and although it does not happen often, its impact is very high to the impact of the construction and it may stop the work on the site (Love et al., 2002).

So, it is very necessary to identify the most important factors that cause variations in the construction industry in Egypt to achieve successful projects. Is the ranking of factors the same in different countries? Many researchers analyze and arrange factors, through different methods is the different methods give the same ranking? This study analyzes and arranges factors that may cause variation in construction projects and grade comparison within the previous researchers. Also, this study analyzes and arranges factors differently and compares them.

\section{MATERIALS AND METHODS}

The main work in this research was divided into five processes, developing a research plan, creating a questionnaire, performing analysis, conducting a discussion and validating results. The process of developing the research plan describes how to create and manage all operations in this search. This includes the method to obtain factors causing variation, the creation of a questionnaire with the assistance of experts using Delphi technology and the distribution of questionnaires to engineers with a different experience for both owners and contractors. The data collected from the questionnaires were analyzed by SPSS Software. Four different methods were used for analysis depending on probability and severity. The risk was identified in the first method as a product of probability multiplication by severity. The hazard in the second method was determined as a product of probability multiplication by the square of severity. The risk was identified in the third method as a product to test the probability and severity of the experiment where the probability, severity and experience values are shown as shown in Table 1. The risk in the fourth method was identified as a product of probability multiplication by intensity but values were taken as in the PMI, (2013) (Edition V) Manual as shown in Table 2. In the conduct discussion process, the raking from the four methods was compared with each other and 
Table 1: The probability, severity and experience

\begin{tabular}{llll}
\hline Rating & Description & Probability (P) & Severity on cost (S) \\
\hline 1 & Very low & $0.10>\mathrm{P}$ & $0.05>\mathrm{I}$ \\
2 & Low & $0.30>\mathrm{P} \geq 0.10$ & $0.10>\mathrm{I} \geq 0.05$ \\
3 & Medium & $0.50>\mathrm{P} \geq 0.30$ & $0.20>\mathrm{I} \geq 0.10$ \\
4 & High & $0.70>\mathrm{P} \geq 0.50$ & $0.40>\mathrm{I} \geq 0.20$ \\
5 & Very high & $\mathrm{P} \geq 0.70$ & $10>\mathrm{E} \geq 5$ \\
\hline
\end{tabular}

Table 2: The probability, severity according to PMBOK

\begin{tabular}{llcc}
\hline Description & Probability (P) Scale & Severity on cost (S) Scale & Rating \\
Very low & $0.10>\mathrm{P}$ & 0.1 & $0.05>\mathrm{I}$ \\
Low & $0.30>\mathrm{P} \geq 0.10$ & 0.3 & $0.10>\mathrm{I} \geq 0.05$ \\
Medium & $0.50>\mathrm{P} \geq 0.30$ & 0.5 & 0.05 \\
High & $0.70>\mathrm{P} \geq 0.50$ & 0.7 & 0.10 \\
Very high & $\mathrm{P} \geq 0.70$ & 0.9 & $0.20>0.10$ \\
\hline
\end{tabular}

it also was compared with the previous studies. The validate results process includes the ratio of confidence interval according to $95 \%$ confidence level with the number of validated respondents.

Create questionnaire: The researcher review previous studies on the causes of variation in the construction industry. The initial questionnaire was created using brainstorming technology to generate and collect multiple factors related to causes of variation. Using Delphi technology, a selected team of experts responded to the initial questionnaires and provided comments on the responses from each round of factors that had been gathered until a consensus had been reached and the final questionnaire had been established.

The final questionnaire was divided into 2 sections, section $\mathrm{A}$ is obtaining demographic information for respondents and section $\mathrm{B}$ focused on the specific reasons for variation orders. To predict risk, respondents were asked to rate the probability and impact of each of the causes of change based on their practical experience in the construction industry. The questionnaires were sent to more than 250 engineers through a field survey and surveying website supported by Google which is Google Forms.

Collect data process: The total number of respondents is 153 respondents where 105 respondents were collected through a field survey and 48 through surveying website supported by Google which is Google Forms.

Table 3 represents the classification of the respondents. The majority of the respondents worked for construction contractor companies $(50.3 \%)$ where the percentage of whom worked for engineering consulting firms was $26.1 \%$ and owner representatives were $23.6 \%$.

Respondents had more than 20 years of experience in the construction field found to be $19.6 \%$ where respondents with 15-20 year's experience was $12.4 \%$, respondents had from $10-15$ year's experience was $20.3 \%$
Table 3: Respondent's classification

\begin{tabular}{lcccc}
\hline Job description & Owner & Consultant & Contractor & Total \\
\hline Experience & & & & \\
$5>\mathrm{E} \geq 3$ & 8 & 7 & 26 & 41 \\
$10>\mathrm{E} \geq 5$ & 4 & 11 & 17 & 32 \\
$15>\mathrm{E} \geq 10$ & 5 & 9 & 17 & 31 \\
$20>\mathrm{E} \geq 25$ & 7 & 6 & 6 & 19 \\
$\mathrm{E} \geq 20$ & 12 & 7 & 11 & 30 \\
Total & 36 & 40 & 77 & 153 \\
\hline
\end{tabular}

who said they had between 5 and 10 year's experience was $20.9 \%$ and respondents claimed to have 5 year's experience or less in the construction industry was $26.8 \%$.

Respondents answered about their major university field of study. The majority of them studied civil engineering $77.1 \%$, architectural engineers were $17.6 \%$ of the respondents, mechanical engineers were $4.6 \%$ and electrical engineers were only $0.7 \%$.

By analyzing the degree of the participants, we found that who had bachelor's degree in engineering was $90.8 \%$ where master's degree holders were $7.8 \%$ and participants had the doctorate in engineering was $1.3 \%$. Table 1 represents the mean of the factors causing variation orders for the four methods separately based on respondent's answers to the distributed questionnaire.

Validate data: The level of confidence tells how the search can be. In this research, the 95\% confidence level was chosen which means that the search can be $95 \%$ certain. The confidence interval is also called the margin of error is plus or minus the results. Often researcher cannot find out exactly the size of the population. The number of the population in this research was considered an infinite number. The selected sample was a random sample of the population concerned.

A statistical calculation is used to ensure that the chosen sample fully represents the population. The formula shown Eq. 1 was used to determine the sample size of unlimited population (Creative Research Systems) (Table 4 and 5). 
Table 4: Mean of the factors

\begin{tabular}{|c|c|c|c|c|}
\hline \multirow[b]{2}{*}{ Factors } & \multicolumn{4}{|l|}{ Mean } \\
\hline & PI & $\mathrm{PI}(\mathrm{PMP})$ & $\mathrm{PI}^{2}$ & PI exp. \\
\hline Change of scope risk & 7.97 & 0.12 & 28.40 & 21.97 \\
\hline Owner's financial problems risk & 11.10 & 0.23 & 46.78 & 29.88 \\
\hline Inadequate project objectives risk & 7.32 & 0.12 & 27.02 & 19.22 \\
\hline Replacement of materials or procedures risk & 10.27 & 0.16 & 35.95 & 27.88 \\
\hline Impediment to prompt decision-making process risk & 11.84 & 0.23 & 48.26 & 31.38 \\
\hline Obstinate nature of owner risk & 10.74 & 0.21 & 43.76 & 27.41 \\
\hline Change in specifications by the owner risk & 9.71 & 0.16 & 34.80 & 25.43 \\
\hline Interference of employer risk & 11.01 & 0.19 & 41.74 & 29.48 \\
\hline Change in design by the consultant risk & 8.93 & 0.15 & 31.84 & 23.62 \\
\hline Errors and omissions in design risk & 11.34 & 0.22 & 45.52 & 29.41 \\
\hline Conflicts among contract documents risk & 10.29 & 0.18 & 39.76 & 28.50 \\
\hline Value engineering risk & 8.04 & 0.11 & 26.24 & 22.61 \\
\hline Design complexity risk & 8.55 & 0.14 & 30.26 & 22.57 \\
\hline Inadequate working drawing details risk & 10.25 & 0.18 & 38.18 & 27.65 \\
\hline Poor knowledge of available materials and equipment risk & 8.69 & 0.14 & 32.11 & 23.08 \\
\hline Inadequate design risk & 9.21 & 0.16 & 35.82 & 24.65 \\
\hline Change in specification by the consultant risk & 8.39 & 0.13 & 29.95 & 21.68 \\
\hline Poor drawings risk & 10.95 & 0.21 & 44.16 & 28.46 \\
\hline Lack of involvement in design risk & 7.93 & 0.13 & 27.73 & 20.39 \\
\hline Unavailability of equipment risk & 8.97 & 0.16 & 34.85 & 23.48 \\
\hline Unavailability of skills risk & 10.17 & 0.19 & 40.77 & 27.71 \\
\hline Contractor's financial difficulties risk & 11.82 & 0.24 & 49.82 & 32.63 \\
\hline Desired profitability risk & 10.60 & 0.18 & 38.41 & 28.81 \\
\hline Differing site conditions risk & 9.41 & 0.15 & 34.63 & 25.52 \\
\hline Poor workmanship risk & 10.25 & 0.19 & 40.61 & 27.54 \\
\hline Unfamiliarity with local conditions risk & 8.18 & 0.13 & 30.51 & 22.54 \\
\hline Fast-track construction risk & 10.55 & 0.18 & 38.92 & 28.63 \\
\hline Poor procurement process risk & 11.01 & 0.20 & 43.45 & 30.80 \\
\hline Long-lead procurement risk & 10.96 & 0.19 & 41.63 & 31.48 \\
\hline Bad sub-contractor or supplier risk & 12.03 & 0.23 & 48.96 & 34.01 \\
\hline Lack of coordination risk & 12.16 & 0.25 & 50.83 & 32.69 \\
\hline Lack of communication between parties risk & 11.51 & 0.23 & 47.97 & 30.42 \\
\hline Lack of strategic planning risk & 11.39 & 0.23 & 47.27 & 30.68 \\
\hline Health and safety risk & 10.42 & 0.20 & 41.25 & 27.49 \\
\hline Weather conditions risk & 7.25 & 0.12 & 25.50 & 18.53 \\
\hline Change in economic conditions risk & 13.86 & 0.32 & 61.94 & 37.14 \\
\hline Sociocultural factors risk & 7.07 & 0.09 & 22.27 & 18.45 \\
\hline Unforeseen problems risk & 10.35 & 0.19 & 40.61 & 27.16 \\
\hline Force majeure risk & 9.24 & 0.18 & 38.59 & 25.52 \\
\hline
\end{tabular}

$$
\mathrm{SS}=\frac{\mathrm{z}^{2} * \mathrm{p}^{*}(1-\mathrm{p})}{\mathrm{C}^{2}}
$$

Where:

$\mathrm{SS}=$ Sample size

$Z=Z$ value according to the confidence level

$\mathrm{p}=$ Percentage picking a choice, expressed as a decimal

$\mathrm{C}=$ Confidence interval, expressed as a decimal

The total number of respondents was 153 . The value of $Z$ was 1.95 where the reporter to $95 \%$ confidence level. Furthermore, the respondent chose one of five categories (very low, low, medium, high or very high) that was $\mathrm{p}(1 / 5)$ was 0.2 . Thus, the confidence period was $6.34 \%$.

After collecting the 153 respondents, the analysis was performed using SPSS Software. The cronbach's alpha for all factors was 0.901 which means it is positive and high. Therefore, the questionnaire is stable and it will be non-contradiction with itself and according to it gives the same results if applied to the same sample.
The null hypothesis $\left(\mathrm{H}_{0}\right)$, No relation that is statistically significant at the $95 \%$ confidence level between job classification and years of experience. The alternative hypothesis for this study $\left(\mathrm{H}_{A}\right)$, there is a relation that is statistically significant at the $95 \%$ confidence level between job classification and years of experience. From the Chi-square test, it was clear that the lowest value of the significance level is: 0.08 which is greater than the value $(\alpha=0.05)$. Thus, accepting the null hypothesis (the job classification does not depend on the years of experience).

After ANOVA analysis, there is no significant difference between the results obtained from contractors, consultants or owners at 0.05 level of confidence. However, there is a significant difference at the 0.05 level of confidence between the results obtained from different experience. To determine the most common causes for variation orders in construction projects in Egypt, the 
Table 5. Ranking of the factors

\begin{tabular}{|c|c|c|c|c|}
\hline \multirow[b]{2}{*}{ Factor } & \multicolumn{4}{|c|}{ Raking } \\
\hline & PI & $\mathrm{PI}(\mathrm{PMP})$ & $\mathrm{PI}^{2}$ & PI Exp. \\
\hline Change in economic conditions risk & 1 & 1 & 1 & 1 \\
\hline Lack of coordination risk & 2 & 2 & 2 & 3 \\
\hline Bad sub-contractor or supplier risk & 3 & 4 & 4 & 2 \\
\hline Impediment to prompt decision-making process risk & 4 & 5 & 6 & 6 \\
\hline Contractor's financial difficulties risk & 5 & 3 & 3 & 4 \\
\hline Lack of communication between parties risk & 6 & 6 & 5 & 9 \\
\hline Lack of strategic planning risk & 7 & 7 & 7 & 8 \\
\hline Errors and omissions in design risk & 8 & 9 & 9 & 12 \\
\hline Owner's financial problems risk & 9 & 8 & 8 & 10 \\
\hline Poor procurement process risk & 10 & 12 & 13 & 7 \\
\hline Interference of employer risk & 11 & 13 & 14 & 11 \\
\hline Long-lead procurement risk & 12 & 14 & 15 & 5 \\
\hline Poor drawings risk & 13 & 10 & 10 & 16 \\
\hline Obstinate nature of owner risk & 14 & 11 & 11 & 22 \\
\hline Desired profitability risk & 15 & 22 & 23 & 13 \\
\hline Fast-track construction risk & 16 & 20 & 20 & 14 \\
\hline Health and safety risk & 17 & 15 & 12 & 21 \\
\hline Unforeseen problems risk & 18 & 17 & 18 & 23 \\
\hline Conflicts among contract documents risk & 19 & 19 & 19 & 15 \\
\hline Replacement of materials or procedures risk & 20 & 24 & 25 & 17 \\
\hline Poor workmanship risk & 21 & 18 & 17 & 20 \\
\hline Inadequate working drawing details risk & 22 & 23 & 22 & 19 \\
\hline Unavailability of skills risk & 23 & 16 & 16 & 18 \\
\hline Change in specifications by the owner risk & 24 & 27 & 27 & 26 \\
\hline Differing site conditions risk & 25 & 28 & 28 & 24 \\
\hline Force majeure risk & 26 & 21 & 21 & 25 \\
\hline Inadequate design risk & 27 & 25 & 24 & 27 \\
\hline Unavailability of equipment risk & 28 & 26 & 26 & 29 \\
\hline Change in design by the consultant risk & 29 & 30 & 29 & 28 \\
\hline Poor knowledge of available materials and equipment risk & 30 & 29 & 30 & 30 \\
\hline Design complexity risk & 31 & 32 & 31 & 32 \\
\hline Change in specification by the consultant risk & 32 & 33 & 32 & 35 \\
\hline Unfamiliarity with local conditions risk & 33 & 31 & 33 & 33 \\
\hline Value engineering risk & 34 & 38 & 38 & 31 \\
\hline Change of scope risk & 35 & 34 & 35 & 34 \\
\hline Lack of involvement in design risk & 36 & 35 & 34 & 36 \\
\hline Inadequate project objectives risk & 37 & 36 & 37 & 37 \\
\hline Weather conditions risk & 38 & 37 & 36 & 38 \\
\hline Sociocultural factors risk & 39 & 39 & 39 & 39 \\
\hline
\end{tabular}

results were ranked in descending order of the most serious factors to the least serious factors according to the questionnaire as shown in Table 5.

\section{RESULTS AND DISCUSSION}

Change in economic conditions: Change in economic conditions ranked as the top cause of variation order in this research due to the new governmental regulations this is also ranked as the 14th in Alaryan (2014)'s and ranked the 16th in Mohammad et al. (2010) researcher.

Lack of coordination: Lack of coordination ranked as the 2nd top cause of variation orders in this research while ranked as the 9th top factor in the research of Mohammad et al. (2010) research and ranked 5th in Dickson et al. (2015)'s study.
Bad sub-contractor or supplier: Bad sub-contractor or supplier ranked as 3rd top cause of change, it's a common cause of variations but it's not ranked as a top cause in previous studies may be this is because main contractors prefer to depend on subcontractors rather than direct labor which increases the difficulty of coordinating the work between different subcontractors and lead to variations.

Impediment to prompt decision-making process by client: Impediment to prompt decision-making process by client ranked 4th top reason for variations in construction projects where (Memon et al., 2014) ranked it as 5th in his research.

Contractor's financial difficulties: Contractor's financial difficulties ranked as the 5 th top cause of change in this research where it ranked as the 10th in Mohammad et al. (2010)'s, Memon et al. (2014) ranked it as the 12th. 


\section{CONCLUSION}

The causes for the variation orders and their effects on the cost and schedule of the project are complex and influenced by several interrelated factors. The risks associated with project variation make it difficult to predict and plan for changes. The objective of this research was to review the literature and field survey of the main causes of the variation and their impact on residential projects.

The five most serious causes were found to be the economic conditions, the lack of coordination between the parties, the bad subcontractor or the vendor by the contractor, impeding the rapid decision-making process of the project owner and the contractor's financial difficulties.

Because of the instability of the economic situation of the country, it was found that the most critical factor that causes variation orders according to the results of the questionnaire was "change in economic conditions" which is very logical and touches the real life in Egypt at present due to the change in the local currency exchange rate and the instability of the economy.

\section{ACKNOWLEDGEMENTS}

The researcher would like to thank many engineers, architects and building contractors for their cooperation in completing the questionnaire used in the survey and support our work to develop studies in managing risks faced by the construction industry.

\section{REFERENCES}

Alaryan, A., 2014. Causes and effects of change orders on construction projects in Kuwait. Intl. J. Eng. Res. Appl., 4: 1-8.

Arain, F.M. and L.S. Pheng, 2005. The potential effects of variation orders on institutional building projects. Facilities, 23: 496-510.

Arain, F.M., S. Assaf and L.S. Pheng, 2004. Causes of discrepancies between design and construction. Archit. Sci. Rev., 47: 237-249.

Chan, D.W.M. and M.M. Kumaraswamy, 1997. A comparative study of causes of time overruns in Hong Kong construction projects. Int. J. Project Manage., 15: 55-63.

Clough, R.H. and G.A. Sears, 1994. Construction Contracting. 6th Edn., Wiley, Hoboken, New Jersey, USA., ISBN:9780471309680, Pages: 584.

Construction Industry Institute, 1986. Impact of various construction contract types and clauses on project performance. University of Texas at Austin, Austin, Texas, USA.
Construction Industry Institute, 1990. The impact of changes on construction cost and schedule. University of Texas, Austin, Texas, USA.

Dell'Isola, A.J., 1982. Value Engineering in the Construction Industry. 3rd Edn., Van Norstrand Reinhold Company, New York, USA., ISBN:9780442262020, Pages: 364.

Dickson, O.D., M. Gerryshom and G. Wanyona, 2015. Variations in civil engineering construction projects in Kenya: Causes and effects. Intl. J. Eng. Res. Technol., 4: 1124-1129.

Fisk, E.R., 1997. Construction Project Administration. 5th Edn., Prentice-Hall, Upper Saddle River, New Jersey, USA., ISBN:9780135022795, Pages: 578.

Geok, O.S., 2002. Causes and improvement for quality problems in design and build projects. BSc Thesis, National University of Singapore, Singapore.

Gray, C. and W. Hughes, 2001. Building Design Management. Butterworth-Heinemann, Oxford, UK., ISBN:9780750650700, Pages: 177.

Hanif, H., M.B. Khurshid, S.M. Lindhard and Z. Aslam, 2016. Impact of variation orders on time and cost in mega hydropower projects of Pakistan. J. Constr. Dev. Countries, 21: 37-53.

Hsieh, T.Y., S.T. Lu and C.H. Wu, 2004. Statistical analysis of causes for change orders in metropolitan public works. Int. J. Project Manage., 22: 679-686.

Ibbs, C.W. and W.E. Allen, 1995. Quantitative impacts of project change: Source document 118. Masters Thesis, University of Texas at Austin, Austin, Texas.

Keane, P., B. Sertyesilisik and A. Ross, 2010. Variations and change orders on construction projects. J. Legal Affairs Dispute Resolution Eng. Constr., 2: 89-96.

Love, P.E.D., G.D. Holt, L.Y. Shen, H. Li and Z. Irani, 2002. Using systems dynamics to better understand change and rework in construction project management systems. Int. J. Project Manage., 20: 425-436.

Memon, A.H., I.A. Rahman and M.F.A. Hasan, 2014. Significant causes and effects of variation orders in construction projects. Res. J. Appl. Sci. Eng. Technol., 7: 4494-4502.

Mohammad, N., A.C. Ani, R.A.O.K. Rakmat and M.A. Yusof, 2010. Investigation on the causes of variation orders in the construction of building project-a study in the state of Selangor, Malaysia. J. Build. Perform., 1: 73-82.

Ndihokubwayo, R., 2008. An analysis of the impact of variation orders on project performance. Ph.D Thesis, Cape Peninsula University of Technology, Cape Town, South Africa. 
O'Brien, J.J., 1998. Construction Change Orders: Impact, Avoidance, Documentation. McGraw-Hill, New York, USA., ISBN:9780070482340, Pages: 383.

PMI., 2013. A Guide to the Project Management Body of Knowledge (PMBOK Guide). 5th Edn., Project Management Institute, Newton Square, PA., USA.

Sanvido, V., F. Grobler, K. Parfitt, M. Guvenis and M. Coyle, 1992. Critical success factors for construction projects. J. Constr. Eng. Manage., 118: 94-111.
Thomas, H.R. and C.L. Napolitan, 1995. Quantitative effects of construction changes on labor productivity. J. Constr. Eng. Manage., 121: 290-296.

Wang, Y., 2000. Coordination issues in Chinese large building projects. J. Manage. Eng., 16: 54-61.

Wu, C.H., T.Y. Hsieh, W.L. Cheng and S.T. Lu, 2004. Grey relation analysis of causes for change orders in highway construction. Constr. Manage. Econ., 22: 509-520. 